\title{
HORACIO QUIROGA Y EL CINE
}

No es difícil demostrar el interés que sentía Quiroga por el cine. Pero 10 que aquí queremos destacar es la relación entre esta preocupación cinematográfica de Quiroga y su modo de escribir.

De este entusiasmo por el cine hay muchas y variadas pruebas. Por una parte, existen varios cuentos relacionados directamente con el cine, entre otros: «Miss Dorothy Phillips, mi esposa», «El espectro», «El puritano» y «El vampiro». Por otra, quedan los artículos escritos por Quiroga en su capacidad de crítico cinematográfico, en Caras y caretas (19191920), en Atlántida (1922) y en El hogar (1927-1928). Escribió también un guión llamado La jangada, basado en dos de sus cuentos, «Los mensú» $\mathrm{y}$ «Una bofetada», y otro basado en «La gallina degollada». También existen una acalorada defensa del cine publicada en Atlántida y una interviú con el título de «Los escritores nacionales y el cine». Además, según nos cuentan sus biógrafos Delgado y Brignole ${ }^{1}$, fundó una efímera «Academia Normal de Cinematografía». El que fundara Quiroga tal academia, dado su entusiasmo por esa nueva forma artística, no tiene nada de particular, pero lo que sí demuestra este hecho es una actitud seria frente al cine compartida por los que le apoyaron en tal empresa. Es preciso recordar esta seriedad por parte del mundo literario frente a la creación cinematográfica para poder ver en su debida perspectiva la importancia del cine como expresión artística durante aquellos años. Cuando Alberti escribe "Yo nací -irespetadme!- con el cine» ${ }^{2}$, refleja, aunque con cierta ironía, la actitud de una generación entera. Entre los escritores que más se destacan en este sentido, aparte del propio Alberti, hay que mencionar a Francisco Ayala, crítico de cine de la Revista de Occidente. El mismo Quiroga hubiera podido escribir las siguientes pa-

\footnotetext{
' José María Delgado y Alberto J. Brignole, Vida y obra de Horacio Quiroga (Montevideo, 1939), pp. 286-289.

${ }^{2}$ Rafael Alberti, Cal y canto (Buenos Aires, 1966), p. 86.
} 
labras de Ayala: "Yo he pensado el cine, mi coetáneo, con amor, con encanto y hasta con cierto desenfreno» ${ }^{3}$. Cuentos como "El vampiro» $\mathrm{y}$ «El espectro» nos demuestran este amor desenfrenado.

Con el interés por el cine podemos incluir un entusiasmo de toda la vida por la fotografía. No hay que olvidar que fue en su calidad de fotógrafo que se internó por primera vez en la selva durante la expedición a San Ignacio dirigida por el poeta Lugones en 1903. El cuento "La cámara oscura» es de los que más claramente atestiguan esta afición.

Pero además de estas pruebas, más bien exteriores de su compenetración con la creación cinematográfica, existen testimonios de esa afinidad en la obra misma de Quiroga. Una de las características que más recuerda la técnica cinematográfica es la capacidad que tienen algunos de los personajes para verse como desde afuera distanciados y superpuestos a lo que los rodea. Se dan casos en «E1 síncope blanco», «E1 hombre muerto», "Su ausencia», «Más allá», «El conductor del rápido», «El espectro» y «Las moscas». Uno de los casos en que más claramente se da esta superposición se encuentra en «Los inmigrantes», cuya última frase termina así: «... quedóse mirando fijamente adelante, al estero venenoso, en cuya lejanía el delirio dibujaba una aldea de Silesia, a la cual él y su mujer, Carlota Phoening, regresaban felices y ricos a buscar a su adorado primogénito" ${ }^{4}$. Aquí queda patente que la visión de la deseada e imposible vuelta a Silesia (imposible, pues el protagonista se está muriendo junto al cadáver putrefacto de su mujer) se ve recortada contra el fondo de lo que realmente rodea al moribundo. Otro ejemplo es aún más inequívocamente una versión verbal de una superposición fotográfica. Se encuentra en el cuento «El regreso de Anaconda»: «Vio de pronto la selva natal en un viviente panorama, pero invertida, y transparentándose sobre ella, la cara sonriente del mensú» ${ }^{5}$. Esta técnica fotográfica, aunque menos avanzada que ahora, ya existía en el cine, por ejemplo, en la versión de Der Golem hecha en 1920. No cabe imaginar que Quiroga no hubiese observado el truco y reflexionado sobre sus posibilidades en la narrativa. Esta cualidad de transparencia la encontramos otra vez en «El vampiro»: «... el espectro sonriente, escotado y translúcido de una mujer» ${ }^{6}$.

$\mathrm{En}$ «Su ausencia» también encontramos otros trucos de afinidad cinematográfica -el flashback empleado para presentar la idea de la doble

${ }^{3}$ Francisco Ayala, Los ensayos: teoría y crítica literaria (Madrid, 1972), p. 439.

${ }^{4}$ Horacio Quiroga, El salvaje (Buenos Aires, 1963), p. 40.

${ }^{5}$ Horacio Quiroga, Los desterrados (Buenos Aires, 1964), p. 30.

${ }^{6}$ Horacio Quiroga, Más allá (Buenos Aires, 1964), p. 29. 
vida del protagonista y un párrafo en que la simultaneidad de la doble conciencia se expresa en una serie de frases entre paréntesis, intercaladas con otra serie de frases, cada serie representando una de las facetas de las dos vidas-. Se trata de una representación en forma cinematográfíca, como si la cámara oscilara repetidamente entre un plano y el otro presentándolos alternativamente.

La capacidad que posee la cámara para enfocar un objeto determinado en la presentación de una escena es otro de los puntos de contacto con el estilo de Quiroga. En su «Carta abierta al señor Benito Lynch» encontramos las siguientes palabras:

La primera virtud se traduce desde luego en la verdad del paisaje y la brevedad concomitante de la impresión. Porque no se nos escapa a los que tenemos ojos que, en toda visión de campo o lo que fuere, sólo dos o tres cosas saltan vivamente a la vista, que son las que resumen y nos dan la sensación total del paisaje; de lo demás no vale la pena hablar. Y no creo que haya error en lo de brusca: toda visión, a efectos de la ídem (sic) que se quiere sugerir al lector, es necesariamente brusca, $u$ original o instantánea, como se quiera ${ }^{7}$.

Habla del arte de escribir, pero es significativo que emplee la palabra «instantánea» con su connotación fotográfica y cinematográfica. Andreetto, en un artículo publicado en 1957, habia de los croquis «alcanzados en instantáneas rápidas, pero pictóricas» ${ }^{8}$, empleando la palabra precisamente en su sentido fotográfico y mostrándose consciente de la clase de técnica empleada por Quiroga. Otro de los pocos críticos que parecen haberse dado cuenta de la afinidad con el cine del arte de Quiroga es Etcheverry. En un artículo publicado en El País dice:

El narrador trata de iluminar un personaje mediante rápidas aproximaciones, utilizando lo que en esencia no es más que técnica fotográfica: son como varias tomas del individuo en cuestión en distintas actitudes; la sucesión de estas tomas da la imagen completa ${ }^{9}$.

Se trata realmente de técnica cinematográfica, no fotográfica, pues es precisamente la película cinematográfica, que se compone de una sucesión de tomas, la que da la imagen completa.

${ }^{7}$ Horacio Quiroga, «Carta abierta al señor Benito Lynch»; 1916, en Obras inéditas y desconocidas, VII (Montevideo, 1970), p. 37.

${ }^{8}$ Miguel Angel Andreetto, "Los cuentos de Horacio Quiroga»: Hoja suelta encontrada en el Archivo Horacio Quiroga, Montevideo, datada 15 octubre 1957.

9 José Enrique Etcheverry, «Teoría y práctica del cuento literario en Horacio Quiroga», en El País (31 agosto y 1 septiembre 1962). 
Entre otros efectos cinematográficos encontramos la siguiente cita de «El conductor del rápido»: "A veces, mientras hablo con alguno mirándolo a los ojos, tengo la impresión de que los gestos de mi interlocutor y los míos se han detenido en estática dureza, aunque la acción prosigue...» ${ }^{10}$. Da la impresión de una brusca detención en el rodaje. Efectos de travelling también se producen, por ejemplo: "Yo la sentí sin mover los ojos, pues los muros del salón cedían llevándose adherida mi vista, huían con extrema velocidad en líneas que convergían sin juntarse nunca. Una interminable avenida de cicas surgió en la remota perspectiva» ${ }^{11}$.

En repetidas ocasiones nos presenta Quiroga un plano de acercamiento: «... cuando de pronto y de golpe los dedos de la mano izquierda se abalanzaron hacia mis ojos convertidos en dos monstruosas arañas verdes... Fui a hablarle y su cara se transformó instantáneamente en un monstruo que saltó sobre mí: no una sustitución, sino los rasgos de la cara desvirtuados, una desmesuración atroz... Todos [los animales] tenían esa facultad abalanzante...» ${ }^{12}$.

Del mismo año data el cuento «El crimen del otro», en que Quiroga nos presenta el fenómeno opuesto. "La vista fija se me iba. Fortunato decrecía hasta convertirse en un ratón que yo miraba» ${ }^{13}$.

Muchos años más tarde vuelve a emplear el truco del acercamiento en «El espectro», uno de los cuentos más visiblemente influidos por el cine. «Enid y yo, juntos e inmóviles en la oscuridad, admirábamos como nadie al muerto amigo, cuyas pestañas nos tocaban casi cuando Wyoming venía desde el fondo a llenar él sólo la pantalla. Y al alejarse de nuevo a la escena del conjunto, la sala entera parecía estirarse en perspectiva» ${ }^{14}$.

Lo antedicho basta para comprobar las conexiones entre la obra de Quiroga y el cine no relacionadas con la presentación monocroma de la materia. Pero es en este punto que encontramos la conexión más obvia y más fundamental. La extraordinaria predilección que demuestra Quiroga por el uso del blanco y negro queda comprobada en un estudio detallado de los colores que emplea en sus seis principales colecciones de cuentos para adultos ${ }^{15}$. Se ve claramente que Quiroga emplea los colores

\footnotetext{
10 Horacio Quiroga, Más allá (Buenos Aires, 1964), p. 49.

"Ibid., p. 36.

${ }^{12}$ Horacio Quiroga, El crimen del otro y otros cuentos (Montevideo, 1942), p. 109.

${ }^{13}$ Ibid., p. 23.

${ }^{14}$ Horacio Quiroga, El desierto (Buenos Aires, 1966), p. 73.

${ }^{15}$ A Study of the Use of Colour Terms in the Six Major Collections of Short Stories by Horacio Quiroga, Ph. D. Thesis by Mercedes Clarasó, St. Andrews, 1976.
} 
más bien con parquedad y con una distribución muy poco corriente, destacándose el blanco y el negro sobre los demás colores. Un análisis de todas las menciones de color en las seis obras estudiadas da el siguiente resultado: blanco, 406; negro, 314; rojo, 136; amarillo, 63; azul, 38; otros, 105. Total, 1.062. Lo más sorprendente de esta lista es el predominio del blanco y del negro. Sobre un total de 1.062 , estos dos colores se encuentran sumados en la proporción de 720. Es decir, que forman aproximadamente unas dos terceras partes del total de las referencias cromáticas. La importancia de esta distribución resulta aún más evidente si se la compara con la de otros autores. Con tal fin se hizo un recuento cromático de las cinco novelas latinoamericanas publicadas durante los años de actividad literaria de Quiroga. La comparación no pudo hacerse con el mismo género, el cuento, por carecer la literatura latinoamericana en esa época de colecciones de cuentos de envergadura e interés comparables con la obra de Quiroga ${ }^{16}$.

Naturalmente, lo que interesa aquí no es el total de referencias de cada autor, ya que la extensión de las obras es variable, lo que importa es la proporción de blanco y negro en relación con los demás colores. Tal operación da aproximadamente los siguientes resultados: Larreta, 1:1; Azuela, 2:3; Rivera, 1:1; Güiraldes, 4:5; Gallegos, 1:1. En Quiroga, como queda visto, la proporción sobrepasa el $2: 1$. En todos encontramos o proporciones más o menos iguales o predominio de los demás colores sobre el blanco y negro. Sólo en Quiroga encontramos la proporción inversa, o sea, de $2: 1$, con un predominio significativo de blanco y negro. Es decir, que en Quiroga hay una desproporción mucho más acusada que en los demás autores, y ésta opera en el sentido contrario. Es evidente, pues, que la parcialidad de nuestro autor por el blanco y negro es un fenómeno realmente fuera de lo común.

Lo curioso es que nadie parece haberse dado cuenta de esta conexión entre el colorido predilecto de Quiroga y la técnica cinematográfica, ni siquiera los dos críticos ya mencionados, Andreetto y Etcheverry. Ambos

Los libros estudiados son los siguientes: Cuentos de amor, de locura y de muerte, 1917; El salvaje, 1920; Anaconda, 1921; El desierto, 1924; Los desterrados, 1926; Más allá, 1935.

${ }^{16}$ Las obras estudiadas son las siguientes: Larreta, La gloria de don Ramiro (1908); Azuela, Los de abajo (1915); Rivera, La vorágine (1923); Güiraldes, Don Segundo Sombra (1926); Gallegos, Doña Bárbara (1929). Se obtuvieron los siguientes resultados:

\begin{tabular}{|c|c|c|c|c|c|c|}
\hline 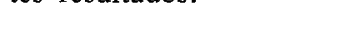 & Larreta & Azuela & Rivera & Gïiraldes & Gallegos & Quiroga \\
\hline Blanco y negro & 299 & 133 & 203 & 199 & 186 & 720 \\
\hline Otros colores $\ldots \ldots \ldots$ & 285 & 218 & 234 & 249 & 177 & 342 \\
\hline
\end{tabular}


aciertan en relacionar el arte de Quiroga con el cine, sin aparentemente caer en la cuenta de que su más estrecha relación consiste en el ya mencionado uso de idéntico colorido -en el caso del cine, por carecer en aquel entonces de otros medios; en el de Quiroga, por lo visto, obedeciendo a motivos de índole artística que vamos a examinar en brevePara mejor comprender estos motivos vale la pena echar un vistazo sobre la actitud de Quiroga sobre el cine sonoro. No fue hasta el año 1927 que apareció la primera película sonora, The Jazz Singer. En la ya mencionada interviú publicada en Atlántida afirma Quiroga que el cine es «mudo por esencia» y que no se le puede considerar como un sustituto del teatro, sino que se tiene que ver como una forma completamente independiente $\mathrm{y}$, sobre todo, visual. La capacidad que tiene la pantalla para representar visualmente los detalles concretos es uno de los atributos del cine que Quiroga más aprecia. Es un rasgo constante de su prosa en la que vemos una acusada dominación de la imagen visual. Casi todo es presentado a base de breves descripciones del mundo material, con uso muy parco de los sustantivos abstractos. Palabras que equivalen casi siempre a cosas, casi nunca a teorías o pensamientos. Para un artista con estas propensiones, ¿qué ventaja puede haber en añadir palabras a lo que podemos ver con nuestros propios ojos? Citamos de «Los escritores nacionales y el cine»: «Llegamos así, de la verdad del escenario a la sobriedad de la expresión, calidad por excelencia del cine como arte interpretativo» ${ }^{17}$. En esta frase nos señala Quiroga las dos desideratas del arte tal como lo entiende él - verdad del escenario, calidad aportada casi automáticamente por el uso de la cámara y sobriedad de la expresión, calidad que depende totalmente en el arte literario de la discreción del autor-. El valor que le atribuye Quiroga a la sobriedad se ve tanto en su forma de escribir como en todo lo que escribió en forma de consejo para los autores noveles, como, por ejemplo, el «Decálogo del perfecto cuentista». Y esta sobriedad es algo que muchos de los amantes del cine temprano supieron apreciar.

Ahora bien: para la mayoría, cualquier innovación técnica es necesariamente un avance. Los pocos que, como Chaplin, Eisenstein, Clair y el propio Quiroga, temían las consecuencias artísticas de la invención del cine sonoro, comprendiendo que acabaría por revolucionar no sólo la técnica cinematográfica, sino todo su modo de ser, toda su concepción desde el punto de vista artístico, perdieron la partida. Como compren-

\footnotetext{
17. Horacio Quiroga, «Los escritores nacionales y el cine», en Walter Rela, Horacio Quiroga: Repertorio bibliográfico anotado, 1897-1971 (Buenos Aires, 1972), p. 57.
} 
dieron ellos, la imagen en blanco y negro, sin aportación de detalles de colorido y sin el elemento sonoro, es una forma básica, inteligible e inequívoca de presentar la realidad concentrando la atención en los elementos más importantes. Es posible burlar, por así decirlo, la multiplicidad de la naturaleza, eligiendo sólo los elementos necesarios para el caso. La diferencia entre una obra artística y un simple reportaje consiste precisamente en esta capacidad de enfocar sólo los detalles apropiados. Quiroga ve con lucidez la necesidad de restringir los medios para la creación artística, lo que se puede apreciar tanto por el estudio de su estilo como por la lectura de su crítica cinematográfica y literaria.

Si nuestro autor, sin embargo, está convencido de esa verdad una vez alcanzada la madurez, no fue así en sus primicias literarias. Dos cosas contribuyeron a encaminarle en una senda muy diferente de la que al final tenía que seguir. Primera, el hecho de empezar a escribir Quiroga precisamente durante los primeros embriagadores años del modernismo. Y segunda, su propia sensibilidad, siempre a flor de piel. Si a estas dos circunstancias se añade la adolescencia del autor, se explica fácilmente el que saliera como resultado un libro, Los arrecifes de coral, en el que se hace caso omiso de todos los valores que más adelante predicará y practicará ese mismo autor. No sobriedad, sino sensibilidad, le parecía entonces la palabra clave para el éxito literio. Y resulta que, con bastante razón, se creía un ser privilegiado en este aspecto. En su artículo «E1 caso Lugones-Herrera y Reissig», escrito un cuarto de siglo más tarde, al describir su amistad con el poeta escribe: «... a mediados de 1900, ambos creíamos poseer también una sensibilidad nueva totalmente extraña al medio ambiente» ${ }^{18}$, y en la página siguiente describe: «La alegría de nuestros comienzos, nuestra inconmensurable fe, no como poetas -Dios me perdone-, sino como poseedores de una nueva, incomprensible y pasmosa sensibilidad» (op. cit., p. 74). El mayor problema, según veía Quiroga las cosas en esa época, consistía simplemente en encontrar el mejor medio para explotar tan pasmosa sensibilidad, y durante una temporada se dedicó a la experimentación con ciertas drogas. Pero paulatinamente fue descubriendo que no era ése su camino; que una sensibilidad hiperestesiada trae peligros tanto en el terreno artístico como en el personal. Y poco a poco llegó a la conclusión de que, para mejor sacar partido de esa sensibilidad, lo que tenía que hacer era restringirla, no ampliarla.

Es interesante ver cómo en el cuento «La patria» Quiroga nos da

${ }^{18}$ Horacio Quiroga, «El caso Lugones-Herrera y Reissig», 1925, en Obras completas (Montevideo, 1970), t. VII, p. 73. 
una especie de parábola que ejemplifica esta verdad. En su intento de establecer en la selva una patria, los animales deciden que necesitan una bandera. Cuando tienen que elegir sus colores no pueden decidirse a excluir ninguno. Por tanto, los incluyen todos en tiritas finas. Cuando llega el momento anhelado de izar la bandera se dan cuenta, estupefactos, de que parece blanca. En este cuento de tendencia moralizadora, tendencia que se ve claramente en otros aspectos de la narración, nos ofrece Quiroga dos verdades sugeridas por este simple suceso. Primero, la verdad cromática, que la suma de todos los colores es el blanco, que equivale a la falta total de color, y segundo, la verdad artística y a la vez moral, que el que se niega a aceptar limitaciones acaba imposibilitado para conseguir lo que se propone. Ante la imposibilidad de reproducir todas las múltiples facetas inherentes en cualquier objeto, el artista tiene que optar. I.os impresionistas trataron de esquivar este problema sacrificando la definición exacta a una indeterminación borrosa y sugestiva. Incapaces de describirlo todo, intentan compensar con una sugestividad que todo lo abarca a fuerza de vaguedad. Quiroga hace exactamente lo contrario. Una de las cosas más notables en el uso que hace de los colores es el hecho de que raras veces se encuentren dos colores juntos, y rarísimas veces más de dos. Y si las impresiones en sí son vagas, no lo es la reacción de Quiroga ante ellas ni trata de escabullirse de la dificultad presentándolas adrede en forma vaga.

A1 mencionar la preferencia de Quiroga por el cine mudo señalamos la necesidad de aceptar algún límite como condición de la creación artística. Pero hay también otra razón para comprender esta preferencia. Si a la imagen cinematográfica le añadimos el sonido, éste necesariamente tiene que obrar en menoscabo de la preeminencia del factor visual. Ahora bien: un examen del estilo de Quiroga deja muy patente el hecho de que es la imagen visual el factor más importante en su presentación del cuento. Esto lo vemos en su predilección por lo concreto. Por ejemplo, al examinar las cuatrocientas menciones de color hechas en forma de sustantivo, vemos que sólo en cuarenta y siete casos se trata de sustantivos abstractos o adjetivos sustantivados. Estos datos en sí bastan para mostrar la preferencia de Quiroga por lo concreto. Si además examinalos cuarenta y siete casos no concretos, veremos que de ellos sólo siete son abstractos. Los otros cuarenta son adjetivos sustantivados, forma netamente más concreta que el sustantivo abstracto.

Otro indicio del afán de presentar el mundo en forma concreta y activa se encuentra en el uso que hace Quiroga del participio de presente y de gran variedad de adjetivos con terminación en -ante y en -iente. No sólo los emplea con frecuencia, sino que también los usa en formas muy 
poco corrientes. Es fácil comprender el atractivo que deben poseer para Quiroga las formas con esta terminación. Por una parte, hay el atractivo de la concisión, evitando el uso de una frase adjetival -en lugar de decir "el sol que quemaba», le basta decir «el sol quemante»-. Si recordamos las palabras de Quiroga en el «Decálogo del perfecto cuentista», «No adjetives $\sin$ necesidad» ${ }^{19}$, es evidente que un adjetivo que tiene a la vez una fuerza verbal además de adjetival tiene que atraerle por su economía. Por otra parte, el hecho de que sea verbal la segunda cara de tal vocablo lo convierte en un instrumento extraordinariamente apropiado para un autor para quien la acción tiene siempre más importancia que la pura descripción, que en Quiroga siempre se encuentra al servicio de la acción. En «El simún», por ejemplo, la descripción del tétrico canal de Paraná y la de las arenas albeantes del desierto tienen su razón de ser desde el punto de vista de la acción, mostrando el efecto que tienen sobre el hombre estos dos ambientes tan distintos. En el participio de presente, cuando se trata de un verbo transitivo, tenemos una fórmula perfecta para introducir las ideas opuestas de lo activo y de lo pasivo. En la palabra «encegueciente», por ejemplo, palabra empleada con frecuencia por Quiroga, tenemos presente la idea del agente que enceguece y, a la vez, la de la persona enceguecida. Esta serie de palabras terminadas en -ante y en -iente que nos recuerdan las formas activas del verbo nos ofrece otra prueba de esa preferencia por lo concreto.

Finalmente, no se pueden dejar estas consideraciones sobre el interés de Quiroga por el cine sin mencionar una faceta bastante original de esta preocupación, o sea, la insinuación varias veces repetida de que en la cinta cinematográfica existe cierto residuo de la vida del artista, y que esta vida, independiente de la verdadera vida de la estrella, puede ser activada al proyectarse la imagen en la pantalla. «El vampiro», «El espectro» y «El puritano» se basan en esta posibilidad. De aquí llega Quiroga a sugerir que existe una posible relación entre el artista representado en la pantalla y el espectador. En «El puritano» nos dice: «Todo se había desvanecido en la nada inerte, dejando en compensación un sendero de lívida y tremenda angustia, que iba desde una butaca vacía hasta un diván espectral» ${ }^{20}$. En «El vampiro», la imagen de la hermosa estrella llega a tener una vida tan independiente que mata a su evocador. $\mathrm{Y}$ en «El espectro», el muerto Duncan Wyoming «sale» de la pantalla para acusar a su mujer y a su amigo intimo. Es precisamente en

19 Horacio Quiroga, «Decálogo del perfecto cuentista», 1927, en Obras completas (Montevideo, 1970), t. VII, p. 87.

${ }^{20}$ Horacio Quiroga, Más allá (Buenos Aires, 1964), p. 83. 
este cuento donde encontramos las palabras «esa alucinación en blanco y negro», refiriéndose Quiroga al fenómeno del cine, palabras que igualmente podrían emplearse como descripción de su propia técnica narrativa. Y es en estos tres cuentos que nos sugiere Quiroga que los límites de esa alucinación quizá no sean exactamente los que solemos suponer y que la evocación de una imagen cinematográfica puede tener consecuencias que van más allá de lo normal. Con la cual sugerencia queda ejemplificado el desenfreno mencionado al principio de esta nota.

University of St. Andrews.

Mercedes Clarasó

Scotland 